\title{
Characterization and Prevalence of a New Porcine Calicivirus in Swine, United States
}

\section{Qiuhong Wang, Kelly Scheuer, Zhenwen Zhang, Wondwossen A. Gebreyes, Bayleyegn Z. Molla, Armando E. Hoet, and Linda J. Saif}

Real-time reverse transcription PCR revealed that new St-Valerien-like porcine caliciviruses are prevalent $(2.6 \%-$ $80 \% ; 23.8 \%$ overall) in finisher pigs in North Carolina. One strain, NC-WGP93C, shares $89.3 \%-89.7 \%$ genomic nucleotide identity with Canadian strains. Whether these viruses cause disease in pigs or humans or are of food safety concern requires further investigation.

$\mathrm{V}$ iruses in the family Caliciviridae are nonenveloped, polyadenylated, single-stranded, positive-sense RNA viruses (1). They have been classified into 5 genera (Norovirus, Sapovirus, Vesivirus, Lagovirus, and Nebovirus) since 2009 (www.ictvonline.org). Later, the nonhuman primate Tulane virus (2) and the porcine StValerien-like viruses (3) were characterized as potential new genera in the Caliciviridae family.

\section{The Study}

Recently, we identified a St-Valerien-like virus, NCWGP93C strain, from a healthy finisher pig in the United States by reverse transcription PCR (RT-PCR) with calicivirus universal primers p290/110 (4,5), followed by direct sequencing and nucleotide BLAST search (www. ncbi.nlm.nih.gov). We further sequenced the genome of NC-WGP93C strain by using primer walking, $3^{\prime}$ and $5^{\prime}$ rapid amplification of cDNA ends (RACE) methods $(3,6,7)$. The NC-WGP93C strain was closely related genetically to the Canadian St-Valerien-like viruses, AB90, AB104, and F15-10 strains (3), sharing 89.3\%$89.7 \%$ nt identity, without insertions or deletions, and similar genomic organization. Complete genomes of strains representing different Caliciviridae genera were selected for a phylogenetic tree (Figure 1). The NC-WGP93C strain

Author affiliations: The Ohio State University, Wooster, Ohio, USA (Q. Wang, K. Scheuer, Z. Zhang, L.J. Saif); and The Ohio State University, Columbus, Ohio, USA (W.A. Gebreyes, B.Z. Molla, A.E. Hoet)

DOI: $10.3201 /$ eid1706.101756 grouped with the Canadian St-Valerien-like viruses to form a potentially new genus within the Caliciviridae family.

Next, we developed a real-time quantitative RTPCR (RT-qPCR) for detection of St-Valerien-like viruses with primers (WGP93-polF1, 5'-TCTAAAG CGTGCACTCTGGGTCAT-3'; WGP93-polR1， 5'-ACC CTTTCTCCACCAGGAACTTCT-3') and probe (WGP93polP1, FAM-ACGAGTTTGTGGACTTCCTCTCGCABHQ) that targeted the RNA-dependent RNA polymerase (RdRp). The assay was performed by using the OneStep RTPCR Kit (QIAGEN, Valencia, CA, USA) and a real-time thermocycler (RealPlex, Eppendorf, Germany). A plasmid DNA carrying the p290/110 amplicon of the NC-WGP93C strain was used to generate a standard curve. The detection limit was 10 genomic equivalents (GE) per $20-\mu \mathrm{L}$ reaction (cycle threshold 37.71), corresponding to $4 \times 10^{4} \mathrm{GE} / \mathrm{g}$ of fecal sample (cut-off cycle threshold 38.00). No other porcine enteric caliciviruses, including sapoviruses (GIII/ Cowden, GVI/JJ681, GVII/LL26 strains) and noroviruses (GII.11/QW48, GII.18/QW101, and GII.19/QW170 strains) $(8,9)$, were detected. This RT-qPCR is sensitive and specific for the detection of St-Valerien-like caliciviruses.

Using the above RT-qPCR, we performed a prevalence study of St-Valerien-like viruses. Pig fecal samples ( $\mathrm{n}=$ 1,567) were collected during May-November 2009 from a study of Salmonella infections in apparently healthy finisher pigs from 3 different swine production systems (3 farms per system, and 4 barns per farm, except for farm RW [3 barns]) located in North Carolina (Table 1) (10). Each barn was treated with 1 of 3 biocides-Biosentry (Biosentry, Inc., Stone Mountain, GA, USA), Synergize (Preserve International, Reno, NV, USA), or VirkonS (Dupont Animal Health Solutions, Sudbury, UK) —or with pressurized water as control (11). One pig per pen

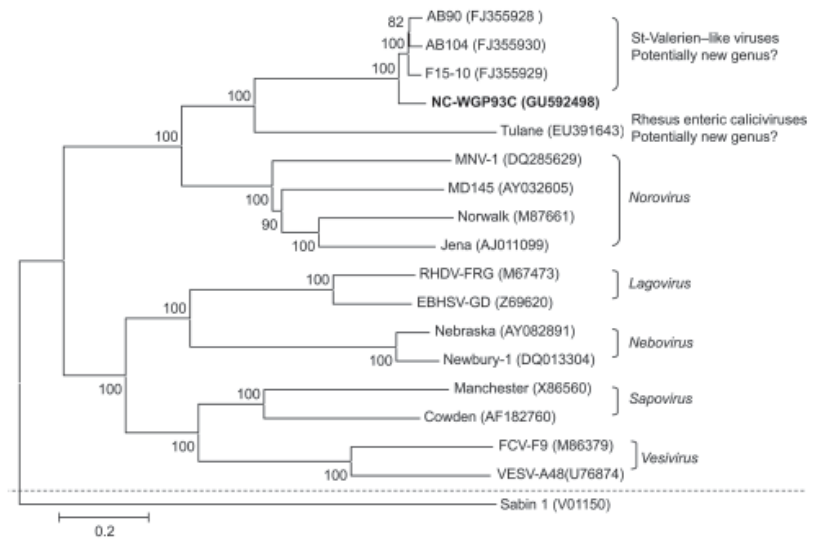

Figure 1. Neighbor-joining phylogenetic tree of caliciviruses based on the complete genomes (nucleotide). The newly identified St-Valerien-like virus NC-WGP93C strain is in boldface. The GenBank accession number of each strain is within parentheses. Bootstrap values are shown near branches. Human Poliovirus Sabin 1 was an outgroup control. Scale bar indicates nucleotide substitutions per site. 


\section{DISPATCHES}

Table 1. Prevalence of St-Valerien-like viruses in finisher swine farms in North Carolina, USA, 2009*

\begin{tabular}{|c|c|c|c|c|c|c|c|}
\hline $\begin{array}{l}\text { System } \\
\text { code }\end{array}$ & $\begin{array}{l}\text { Farm } \\
\text { code }\end{array}$ & $\begin{array}{c}\text { Barn } \\
\text { treatment }\end{array}$ & $\begin{array}{l}\text { Sampling } \\
\text { month }\end{array}$ & $\begin{array}{l}\text { No. individual } \\
\text { samples }\end{array}$ & $\begin{array}{l}\text { No. pooled } \\
\text { samples }\end{array}$ & $\begin{array}{c}\text { Barn level, no. } \\
\text { positive/total (\%) }\end{array}$ & $\begin{array}{c}\text { Farm level, no. } \\
\text { positive/total (\%)† }\end{array}$ \\
\hline BC1 & $\mathrm{BH}$ & Water & Aug & 48 & 10 & $4 / 10(40.0)$ & $8 / 40(20.0)^{b c}$ \\
\hline $\mathrm{BC} 1$ & $\mathrm{BH}$ & $\mathrm{BIO}$ & Aug & 48 & 10 & $2 / 10(20.0)$ & \\
\hline $\mathrm{BC} 1$ & $\mathrm{BH}$ & SYN & Aug & 48 & 10 & $0 / 10$ & \\
\hline $\mathrm{BC} 1$ & $\mathrm{BH}$ & VIR & Aug & 48 & 10 & $2 / 10(20.0)$ & \\
\hline $\mathrm{BC} 1$ & EW & Water & Jul & 42 & 10 & $0 / 10$ & $1 / 39(2.6)^{c}$ \\
\hline $\mathrm{BC} 1$ & EW & $\mathrm{BIO}$ & Jul & 39 & 9 & $0 / 10$ & \\
\hline $\mathrm{BC} 1$ & EW & SYN & Jul & 47 & 10 & $1 / 10(10.0)$ & \\
\hline $\mathrm{BC} 1$ & EW & VIR & Jul & 48 & 10 & $0 / 10$ & \\
\hline $\mathrm{BC} 1$ & WL & Water & May & 47 & 10 & $10 / 10(100.0)$ & $32 / 40(80)^{a}$ \\
\hline $\mathrm{BC} 1$ & WL & $\mathrm{BIO}$ & May & 47 & 10 & $10 / 10(100.0)$ & \\
\hline $\mathrm{BC} 1$ & WL & SYN & May & 46 & 10 & $2 / 10(20.0)$ & \\
\hline $\mathrm{BC} 1$ & WL & VIR & May & 48 & 10 & $10 / 10(100.0)$ & \\
\hline $\mathrm{BC} 2$ & DC & Water & Nov & 39 & 9 & $4 / 9(44.4)$ & $13 / 37(35.1)^{b}$ \\
\hline $\mathrm{BC} 2$ & DC & $\mathrm{BIO}$ & Nov & 45 & 10 & $7 / 10(70.0)$ & \\
\hline $\mathrm{BC} 2$ & DC & SYN & Nov & 35 & 8 & $2 / 8(25.0)$ & \\
\hline $\mathrm{BC} 2$ & DC & VIR & Nov & 48 & 10 & $0 / 10$ & \\
\hline $\mathrm{BC} 2$ & $\mathrm{FF}$ & Water & Oct & 43 & 10 & $1 / 10(10.0)$ & $3 / 40(7.5)^{c}$ \\
\hline $\mathrm{BC} 2$ & FF & $\mathrm{BIO}$ & Oct & 48 & 10 & $1 / 10(10.0)$ & \\
\hline $\mathrm{BC} 2$ & $\mathrm{FF}$ & SYN & Oct & 40 & 10 & $0 / 10$ & \\
\hline $\mathrm{BC} 2$ & $\mathrm{FF}$ & VIR & Oct & 48 & 10 & $1 / 10(10.0)$ & \\
\hline $\mathrm{BC} 2$ & RW & $\mathrm{BIO}$ & May & 45 & 10 & $0 / 10$ & $2 / 30(6.7)^{\mathrm{C}}$ \\
\hline $\mathrm{BC} 2$ & RW & SYN & May & 48 & 10 & $2 / 10(20.0)$ & \\
\hline $\mathrm{BC} 2$ & RW & VIR & May & 46 & 10 & $0 / 10$ & \\
\hline BC3 & GO & Water & Nov & 46 & 10 & $1 / 10(10.0)$ & $8 / 40(20)^{b c}$ \\
\hline $\mathrm{BC} 3$ & GO & $\mathrm{BIO}$ & Aug & 45 & 10 & $1 / 10(10.0)$ & \\
\hline $\mathrm{BC} 3$ & GO & SYN & Nov & 46 & 10 & $4 / 10(40.0)$ & \\
\hline $\mathrm{BC} 3$ & GO & VIR & Aug & 46 & 10 & $2 / 10(20.0)$ & \\
\hline BC3 & TE & Water & Jul & 47 & 10 & $4 / 10(40.0)$ & $12 / 39(30.8)^{b}$ \\
\hline BC3 & TE & $\mathrm{BIO}$ & Jul & 38 & 9 & $2 / 9(22.2)$ & \\
\hline $\mathrm{BC} 3$ & TE & SYN & Jul & 40 & 10 & $4 / 10(40.0)$ & \\
\hline $\mathrm{BC} 3$ & TE & VIR & Jul & 47 & 10 & $2 / 10(20.0)$ & \\
\hline BC3 & TT & Water & Jul & 42 & 10 & $1 / 10(10.0)$ & $3 / 39(7.7)^{c}$ \\
\hline $\mathrm{BC} 3$ & TT & $\mathrm{BIO}$ & May & 45 & 10 & $0 / 10$ & \\
\hline $\mathrm{BC} 3$ & TT & SYN & Jul & 38 & 9 & $2 / 9(22.2)$ & \\
\hline $\mathrm{BC} 3$ & TT & VIR & May & 46 & 10 & $0 / 10$ & \\
\hline Total & & & & 1567 & 344 & $82 / 344(23.8)$ & \\
\hline \multicolumn{8}{|c|}{$\begin{array}{l}\text { *BIO, Biosentry (Bisentry, Inc., Stone Mountain, GA, USA); SYN, Synergize (Preserve International, Reno, NV, USA; VIR, VirkonS (Dupont Animal Health } \\
\text { Solutions, Sudbury, UK). } \\
\text { tSuperscript letters indicate significance, i.e., values between farms labeled with different letters differed significantly, but values between farms labeled } \\
\text { with the same letter did not differ significantly. } p<0.05 \text { by binomial proportion test. }\end{array}$} \\
\hline
\end{tabular}

was sampled at 26-28 weeks of age. Fecal samples were collected directly from the rectums of selected individual pigs (based on convenience); sterile gloves and cups were used to prevent contamination from the environment and between samples. In the laboratory, 4-5 individual samples from the same barn were pooled and stored $\left(-20^{\circ} \mathrm{C}\right)$, resulting in 344 pooled fecal samples for the prevalence study. RNA was extracted from $10 \%$ (wt/vol) fecal suspensions by using the $5 \times$ MagMAX-96 Viral 1 Kit and the RNA extraction robot MagMax Express Magnetic Particle Processor (Applied Biosystems, Foster City, CA, USA). The relationship and differences in prevalence among the various biocide treatments (barns), farms, and production systems were assessed by $\chi^{2}$ and binomial proportion tests (SAS Institute, Inc., Cary, NC, USA). A $p$ value of $<0.05$ was considered significant.

All 9 swine farms were positive for St-Valerien-like viruses. Overall prevalence was $23.8 \%$ (range $2.6 \%$ $80.0 \%$ ) (Table 1). The prevalence in farm WL (32/40; $80.0 \%$ ) was significantly higher than that in the other 8 farms, suggesting that an outbreak occurred at this farm during sampling. The prevalence in production system BC1 $(41 / 119 ; 34.5 \%)$ was significantly higher than that in production system $\mathrm{BC} 2(18 / 107 ; 16.8 \%)$, but not $\mathrm{BC} 3$ $(23 / 118 ; 19.5 \%)$. Differences among the 3 production systems were determined to be primarily due to the origin of the pigs. Each production system is fully independent with their own genetics/breeding units, farrowing sites where 
New Porcine Calicivirus in Swine, USA

Table 2. Prevalence of St-Valerien-like viruses from historical pig fecal samples collected during 2002-2005, United States*

\begin{tabular}{|c|c|c|c|c|c|}
\hline \multirow[b]{2}{*}{ Swine farm } & \multicolumn{5}{|c|}{ \% Pigs (no. positive/total no.) } \\
\hline & $\begin{array}{l}\% \text { Nursing pigs, } \\
1-3 \text { wk }\end{array}$ & $\begin{array}{c}\% \text { Post-weaning pigs, } \\
3-10 \mathrm{wk}\end{array}$ & $\begin{array}{c}\% \text { Finisher pigs, } \\
10-24 \mathrm{wk}\end{array}$ & $\%$ Sows, $>1$ y & $\%$ Total \\
\hline Ohio A & $0(0 / 14)$ & $0(0 / 12)$ & $0(0 / 22)$ & $0(0 / 13)$ & $0(0 / 61)$ \\
\hline Ohio B & $0(0 / 31)$ & $0(0 / 45)$ & $0(0 / 45)$ & $0(0 / 30)$ & $0(0 / 151)$ \\
\hline Ohio C & $0(0 / 15)$ & $0(0 / 12)$ & $0(0 / 6)$ & $0(0 / 28)$ & $0(0 / 61)$ \\
\hline Ohio D & $0(0 / 8)$ & $0(0 / 10)$ & NA & NA & $0(0 / 18)$ \\
\hline North Carolina A & NA & NA & $0(0 / 5)$ & NA & $0(0 / 5)$ \\
\hline North Carolina B & NA & NA & $53(10 / 19)$ & NA & $53(10 / 19)$ \\
\hline Michigan A & NA & NA & $2(1 / 60)$ & NA & $2(1 / 60)$ \\
\hline Total & $0(0 / 68)$ & $0(0 / 79)$ & $7(11 / 157)$ & $0(0 / 71)$ & $3(11 / 375)$ \\
\hline
\end{tabular}

the sampled pigs originated, etc. Our findings suggest that breed differences or incidence of infection in pigs at earlier production stages might affect incidence at the sampled finisher stage. Overall, we found no statistically significant difference in prevalence among the treatments (biocides and water control) (data not shown). These results are consistent with the environmental stability of caliciviruses and their resistance to many disinfectants (1).

We also tested by RT-qPCR historical RNA samples extracted from pig fecal samples collected from December 2002 to March 2005 from 2 North Carolina farms, 4 Ohio farms, and 1 Michigan farm $(n=375)$ (Table 2). These RNA samples were from a previous study of the prevalence of porcine noroviruses and sapoviruses and have been stored at $-70^{\circ} \mathrm{C}$ since 2005 (12). St-Valerien-like viruses were detected in 1 North Carolina swine farm in 2003 (10/19 samples; 53\%). Only 1 of 60 samples collected in 2002 from the Michigan farm showed a weak positive result $\left(3.3 \times 10^{5}\right.$ $\mathrm{GE} / \mathrm{g})$. No St-Valerien-like viruses were detected in the pigs of different ages on the 4 Ohio farms. These results suggest regional differences in the distribution of this new virus.

Representative St-Valerien-like virus strains were selected on the basis of collection sites (Tables 1,2):

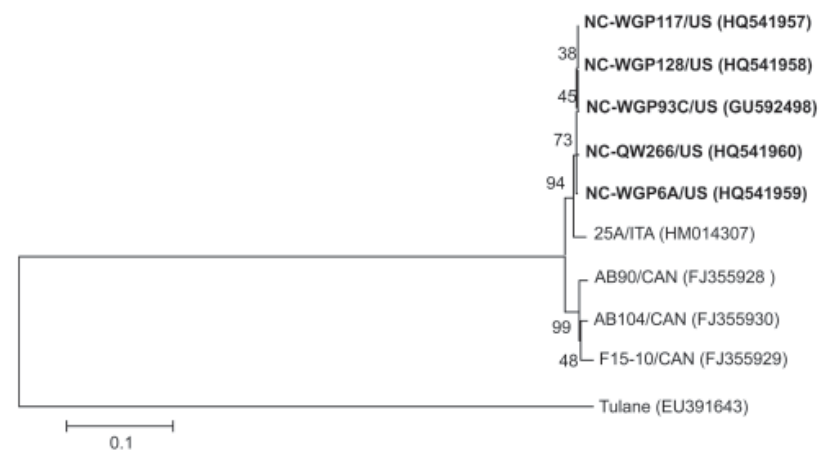

Figure 2. Neighbor-joining phylogenetic tree of St-Valerien-like viruses based on the predicted capsid viral protein 1 sequences (516 aa). The newly identified US St-Valerien-like virus strains are in boldface. The GenBank accession number of each strain is within parentheses. Bootstrap values are shown near branches. Rhesus monkey Tulane calicivirus was an out-group control. Scale bar indicates amino acids substitutions per site.
NC-WGP6A (BC2, FF, BIO), NC-WGP117 (BC1, WL, $\mathrm{BIO}$ ), NC-WGP128 (BC1, WL, VIR), and 1 historic sample NC-QW266 (NC farm B). Because of low virus titers, the positive samples from production system BC3 and Michigan could not be further amplified. The $3^{\prime}$ end, 2,511-nt fragments, including the predicted partial RdRp, complete capsid viral protein (VP) 1 , and minor structural protein VP2 genes were sequenced to examine the genetic variation among St-Valerien-like viruses. The 5 strains from the United States share 97.0\%-99.9\% nt identity in this region. Strains from the United States, the recently reported strain from Italy $(25 \mathrm{~A})$, and the strains from Canada $(3,13)$ share $96.4 \%-100 \%, 95.9 \%-100.0 \%$, and $92.0 \%-100 \%$ aa identities for the partial RdRp (167 aa), VP1 and VP2, respectively. These results suggest that there is only 1 genotype within this potentially new genus (Figure 2 ), although the strain from Italy clusters with strains from the United States.

\section{Conclusions}

St-Valerien-like viruses have been detected in Canada, the United States, and Italy. The prevalence of St-Valerienlike viruses in finisher pigs in North Carolina was $23.8 \%$. No such viruses were detected in swine samples from Ohio collected during March 2003-March 2005. For a proposed new genus, it is critical to determine if St-Valerien-like viruses are present in other regions or species and to examine the genetic diversity among strains. Because these viruses are genetically closest to Tulane virus and human noroviruses $(2,3)$, this information is useful in examining their potential for interspecies transmission and in controlling the spread of new viruses. Whether StValerien-like viruses cause disease in pigs or humans or cause food safety concerns requires further investigation.

\section{Acknowledgments}

We thank Juliette Hanson for assistance with sample transport and Hong Liu for assistance in statistical analyses.

This work was supported by grants from the National Pork Board (\#08-183) and the National Institutes of Health 
(1R21AI081009-2, U01AI08001, and R01AI056351). Salaries and research support were provided by state and federal funds provided to the Ohio Agricultural Research and Development Center (OARDC), The Ohio State University. Sequencing was performed at the Molecular and Cellular Imaging Center, OARDC. The work was done at Food Animal Health Research Program, OARDC, Department of Veterinary Preventive Medicine, The Ohio State University, Wooster, Ohio.

Dr Wang is a research scientist and adjunct assistant professor in the Food Animal Health Research Program, Department of Veterinary Preventive Medicine, Ohio Agricultural Research and Development Center, The Ohio State University, Wooster, Ohio. Her research interests involve diagnosis, epidemiology and characterization, cell culture adaptation, and food safety aspects of enteric calicivirus infections.

\section{References}

1. Green KY. Caliciviridae: the noroviruses. In: Knipe DM, Howley PM, editors. Fields virology. 5th ed. Philadelphia: Lippincott Williams \& Wilkins; 2007. p. 949-79.

2. Farkas T, Sestak K, Wei C, Jiang X. Characterization of a rhesus monkey calicivirus representing a new genus of Caliciviridae. J Virol. 2008;82:5408-16. doi:10.1128/JVI.00070-08

3. L'Homme Y, Sansregret R, Plante-Fortier E, Lamontagne AM, Ouardani M, Lacroix G, et al. Genomic characterization of swine caliciviruses representing a new genus of Caliciviridae. Virus Genes. 2009;39:66-75. doi:10.1007/s11262-009-0360-3

4. Jiang X, Huang PW, Zhong WM, Farkas T, Cubitt DW, Matson DO. Design and evaluation of a primer pair that detects both Norwalk- and Sapporo-like caliciviruses by RT-PCR. J Virol Methods. 1999;83:145-54. doi:10.1016/S0166-0934(99)00114-7
5. Le Guyader F, Estes MK, Hardy ME, Neill FH, Green J, Brown DW, et al. Evaluation of a degenerate primer for the PCR detection of human caliciviruses. Arch Virol. 1996;141:2225-35. doi:10.1007/ BF01718228

6. Scotto-Lavino E, Du G, Frohman MA. 3' end cDNA amplification using classic RACE. Nat Protoc. 2006;1:2742-5. doi:10.1038/ nprot.2006.481

7. Scotto-Lavino E, Du G, Frohman MA. 5' end cDNA amplification using classic RACE. Nat Protoc. 2006;1:2555-62. doi:10.1038/ nprot.2006.480

8. Wang QH, Han MG, Funk JA, Bowman G, Janies DA, Saif LJ. Genetic diversity and recombination of porcine sapoviruses. J Clin Microbiol. 2005;43:5963-72. doi:10.1128/JCM.43.12.5963-5972.2005

9. Wang QH, Han MG, Cheetham S, Souza M, Funk JA, Saif LJ. Porcine noroviruses related to human noroviruses. Emerg Infect Dis. 2005; 11:1874-81.

10. Molla B, Sterman A, Mathews J, Artuso-Ponte V, Abley M, Farmer $\mathrm{W}$, et al. Salmonella enterica in commercial swine feed and subsequent isolation of phenotypically and genotypically related strains from fecal samples. Appl Environ Microbiol. 2010;76:7188-93. doi:10.1128/AEM.01169-10

11. Zewde BM, Robbins R, Abley MJ, House B, Morrow WE, Gebreyes WA. Comparison of Swiffer wipes and conventional drag swab methods for the recovery of Salmonella in swine production systems. J Food Prot. 2009;72:142-6.

12. Wang QH, Souza M, Funk JA, Zhang W, Saif LJ. Prevalence of noroviruses and sapoviruses in swine of various ages determined by reverse transcription-PCR and Microwell hybridization assays. J Clin Microbiol. 2006;44:2057-62. doi:10.1128/JCM.02634-05

13. Di Martino B, Martella V, Di Profio F, Ceci C, Marsilio F. Detection of St-Valerien-like viruses in swine, Italy. Vet Microbiol. Epub 2010 Oct 16.

Address for correspondence: Qiuhong Wang, Food Animal Health Research Program, Ohio Agricultural Research and Development Center, The Ohio State University, 1680 Madison Ave, Wooster, OH 44691, USA; email: wang.655@osu.edu

\section{Get the content you want delivered to your inbox.

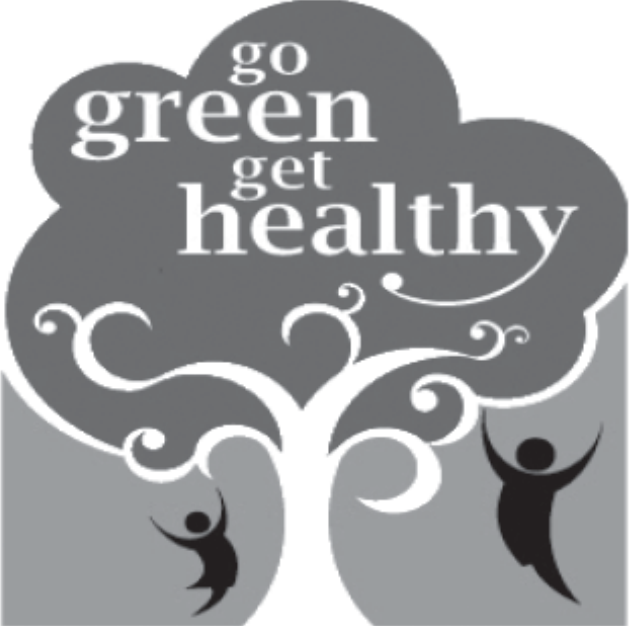 \\ Table of Contents \\ Podcasts \\ Ahead of Print Articles Medscape CME" Specialized Content}

\section{Online subscription: www.cdc.gov/ncidod/eid/subscrib.htm}

